\title{
EDITORIALS
}

\section{Making Transparency Matter}

\author{
David J. Rothman, PhD \\ Center on Medicine as a Profession, Columbia College of Physicians \& Surgeons, New York, NY, USA.
}

$\mathrm{J}$ Gen Intern Med 27(3):266-7

DOI: $10.1007 / \mathrm{s} 11606-011-1971-7$

() Society of General Internal Medicine 2012

$\mathrm{O}$ ver the past five years, the influence of drug company gifts and payments on physicians has received unprecedented attention from leaders of academic medical centers and professional medical societies, regulators at state and federal agencies, health policy researchers, and journalists. Nothing better captures the transformation in outlook and policy than the Sunshine Act provisions, championed by Senator Charles Grassley and now part of the Affordable Health Care Act. Beginning in 2013, drug and device companies must report annually to the Department of Health and Human Services their payments and gifts to physicians; the data-including physician name, address, and exact amount - will then be posted on a searchable website. For the first time, all emoluments that physicians receive from the pharmaceutical and device industry will be transparent and a matter of public record.

Although a substantial literature examines the causes and implications of the new drive to transparency, less attention has been devoted to the public and patient perspective. Do they care? Does the information truly matter to them? Perhaps most important, are they likely to consult the data and act on it, a question that recent research has begun to explore. ${ }^{1}$

The article by Grande et al. in this issue of the JGIM reports that a little over half of respondents in a 2006 telephone survey believe that physicians accept gifts from companies - the proportion is somewhat higher (by 7\%) among college graduates. ${ }^{2}$ Then, using a well-established "trust scale," Grande et al. present what they consider their major finding: those who believe physicians take industry gifts have a lower trust in doctors and more suspicion of health care than those who do not. The authors readily concede that their survey data cannot establish a direct cause and effect relationship between the two attitudesand they did not ask about actual behaviors. Thus, we cannot know whether individuals who hold these two positions act any differently than others.

The findings do contribute to a growing consensus that many patients, when asked, express an interest in, and

Published online January 10, 2012 concern about, the financial relationships between physicians and industry. ${ }^{3}$ However, attitudes vary widely. A 2010 meta-analysis of the literature on financial disclosures reported that $27 \%$ to $56 \%$ of patients thought that gifts affected physicians' prescribing patterns. But at the same time, the authors were uncertain whether this view affected patients' choices about treatment. Although the articles they reviewed established that a good number of patients believed that "gifts affect the cost and quality of care and that these gifts influence [physicians'] clinical judgment, "fewer believed that disclosure would affect their decision-making.",

The open question is whether patients, by their own accord, will search for physicians' financial information on the new databases and then act on it. Given the public's use of other information sites, there is ample reason to suspect that they may not. It appears that neither patients nor referring cardiologists diligently consult the New York State database on surgeon and hospital outcomes for coronary artery bypass surgery. Nor do patients seem to be making decisions on where to seek care based on the federal registry of hospital performance as measured by such indices as levels of noise and quality of food. Because data exists and can be relatively easily retrieved is no guarantee that the public will consult the information, let alone use it to guide their choices. ${ }^{5}$ As a recent survey of health care consumers, conducted by the California HealthCare foundation, reported: "Despite increased overall use of the Web to access health materials, only $26 \%$ of Internet users surveyed sought out ratings information on physicians or other health care professionals ... only $1 \%$ actually made a change in their health care decisions based on ratings." 6

None of these findings should be interpreted to mean that the commitment to transparency is unimportant. In the first instance, they pose an important yet difficult challenge. What can be done to educate or train patients to examine the financial transaction data, pose questions to their doctors, and then, as necessary, make health care decisions? Would it be useful to have physicians give their patients a handout with all their financial ties listed in detail? Should their health care organizations be posting the data on their websites? Should doctors be encouraged or even mandated to have a frank discussion with their patients about their ties to industry? Should all these methods be followed? We simply do not know.

What we do know, however, is that this information is highly relevant to the leaders of health care institutions, 
perhaps even more so than to the consumers of health care. Take the case of the coronary artery bypass surgery outcome data in New York. It appears that hospitals with the worst outcomes altered their behaviors; by administrators' directive or by surgeons' choice, low performers left the field and were replaced by more competent surgeons. Outcomes then improved. It is possible that healthy patients who were not in an emergency situation did exercise choice by going to a better performing institution. But it seems even more likely that the low ranking institutions instituted changes so as to repair their reputations and better serve patients. ${ }^{7}$

By extension, the data on financial transactions between physicians and industry will have the maximum impact to the degree that the heads of health care institutions use the information to better manage conflicts of interest. Efforts to influence patient choices are important, but it is even more crucial that leaders consult the disclosures and use them, as necessary, to reach decisions about participation or disqualification. If an AMC or hospital chooses to post physicians' financial information on its website for patients to see, that is all to the good. Better yet, AMCs and hospitals should access the data to verify individual disclosures so as to better manage faculty and physician conflicts of interest. Not all industry relationships necessarily warrant concern or disqualification and we do want clinicians and investigators to share their medical and scientific knowledge and insights with industry. But full and accurate information about the nature and magnitude of the ties would help deans, chairs, and chiefs of services better determine who ought to be lecturing (or not lecturing) to medical students and who should be serving (or not serving) on formulary and device purchasing committee.

By the same token, professional medical societies should turn to the information when selecting program chairs, continuing medical education presenters, and members of guideline writing committees. Medical journal editors should use the data to help them choose appropriate reviewers for submitted articles and to verify that the conflict of information forms that authors submit are fully accurate. In this same spirit, the NIH should consult the data when selecting study groups or consensus conference members, and so should the FDA when establishing review panels. Again, the intent is not to demonize industry or disqualify every recipient of payments from all activities; and we all appreciate that money is only one source of potential bias. Still, the data will help to insure that both the reality of conflict of interest and the appearance of conflict of interest are taken into account when appointments are made.

In sum, it is best to move on all fronts. Patients should be encouraged along with administrators and editors to take advantage of the new transparency. But whatever patients choose to do or not to do, the leaders of our health care institutions should use disclosure data to better guide their decision-making.

Corresponding Author: David J. Rothman, $\mathrm{PhD}$; Center on Medicine as a Profession, Columbia College of Physicians \& Surgeons, 630 West 168th Street, PH1525, New York, NY 10032, USA (e-mail: Djr5@columbia.edu).

\section{REFERENCES}

1. Fung $\mathbf{C H}$, Lim YW, Mattke S, et al. Systematic review: the evidence that publishing patient care performance data improves quality of care. Ann Intern Med. 2008;148:111-23. See specifically pg. 121.

2. Grande $\mathbf{D}$, Shea JA, Armstrong $\mathbf{K}$. Pharmaceutical industry gifts to physicians: patient beliefs and trust in physicians and the health care system. J Gen Intern Med. 2012; doi: 10.1007/s11606-011-1760-3.

3. Jastifer J, Roberts S. How the pharmaceutical industry influences doctors: patients' awareness of and attitudes toward gifts from pharmaceutical companies to physicians. Int J Health Serv. 2009;39(2):405-14.

4. Licurse A, Barber E, Joffe S, Gross C. The impact of disclosing financial ties in research and clinical care: a systematic review. Arch Intern Med. 2010;170(8):675-8.

5. Archon F, Graham M, Weil D. Full Disclosure: The Perils and Promise of Transparency. Cambridge: Cambridge University Press; 2007.

6. California HealthCare Foundation. Snapshot - just looking: consumer use of the internet to manage care. 2008. Available from: http://www.chcf. org/publications/2008/05/just-looking-consumer-use-of-the-internet-tomanage-care [accessed 13 December 2011].

7. Cutler DM, Huckman RS, Landrum MB. The role of information in medical markets: an analysis of publicly reported outcomes in cardiac surgery. Natl Bur Econ Res. 2004;94(2):342-6. 